\title{
Effect of Using Simulated Learning on Nurses Performance in Applying Health Education Process
}

\author{
1Shaimaa Mostafa Abd Elaziz Almarhomy, 2Dr. Sahar Mohamed Soliman, \\ 3Dr. Samia Mahmoud Abd El Mouty. \\ . 1B.Sc, Faculty of nursing, Mansoura University ,2 Professor of Community Nursing, Faculty of \\ Nursing, Mansoura University,3Assistant Professor of Community Nursing, Faculty of Nursing, \\ Mansoura University, Egypt \\ E-mail of corresponding author: sh.moustafa87@gmail.com.
}

\begin{abstract}
Health education has been regarded as an important aspect of nursing for years. To be able to provide health education, nurses need to know about the content of health education. Simulations in nursing education are indispensable. The study aims to assess using of simulation education on nurse's performance of applying health education process. A quasi experimental design was utilized in this study. Purposive sample included all nurses (70) whom assigned to work in outpatient clinics of Aga Central Hospital at Dakahlia governorate. Nurses' qualifications include baccalaureates, technician and diploma. Four tools were used for collecting data in this study: self-administered structured questionnaire to assess demographic and qualification data, self-administered structured questionnaire to assess nurses' knowledge regarding health education and structured observation checklist to assess nurses' performance regarding the application of health education process, self-administered structured questionnaire to assess: nurses' perception regarding importance of health education and the use of simulation learning. Results: This study showed that the average scores of nurses' knowledge and performance about health education process is significantly higher after applying the simulated learning sessions. Conclusion: present study revealed that nurses' knowledge and performance related to health education were poor in pre-program while their knowledge and performance improved in post program. Recommendations: Staff development educators can create carefully crafted simulations that will assist in developing the expertise needed to meet the current challenges in nursing and healthcare at large.
\end{abstract}

Keywords: nurse education, simulation, health education process 


\section{Introduction}

Education in globe is a teaching and learning process aims at socializing individuals and improving their development. Education is considered as an extensive system with different methods (Tanaka \& Tamura, 2016). Improve the awareness about continuing education for health care providers is needed because there is an ongoing lack of experienced and well-trained health care providers around the world as stated by Beilner and Leonard (2017).

Continuing education help to improve health care providers' capabilities such as the way of response to societal needs, caring, creativity, critical thinking and insightful about moral and ethical issues of the community (ANA, 2015).

Educators are facing many of challenges in educating healthcare providers. Therefore, the educators should select an educational strategy that link knowledge with clinical practice and save patients; the appropriate one is simulation. Simulation strategy is a technique replaces real experience with the guided experience in an interactive manner (Ander \& Love, 2017). Simulation aims to improve patient safety and helping health care providers to link knowledge with clinical practice (Nestel et al, 2017).

Community health nurse has a vital role and responsibility as a health educator, to communicate with people in different ways to provide health information, behavioral modifications, motivational approach, guidance approach and participation approach. Nurses in health education focuses on people and on action using psychological, social and intellectual dimensions relating to activities. These activities influence the abilities of people to make informed decisions. The main goal of health education is improving the basic quality of life (Holzemer \& Klainberg, 2014, Potter, Perry, Stockert\& Hall, 2018 \& Ervin \& Kulbok, 2018).

Various methods and media can be used in health education to keep effective learning "lecture method, demonstration, group discussion, role playing, case study, brain storming and workshop". Visual, audio and audiovisual models these media are used to communicate information and knowledge. Health education can be conducted in health care settings, homes, schools and work sites (Clement, 2012).

Simulation range from low fidelity simulation to high fidelity simulation improves nurses' educational performance, knowledge and attitudes (Jung-Hee, Jin-Hwa \& Sujin, 2020). In the light of this knowledge, the current study will be conducted to assess the effect of using simulation learning on nurses' performance in applying health education process.

Aim of the study: The aim of this study is to assess using of simulation education on nurse's performance of applying health education process.

\section{Method:}

Design: Quasi experimental design was adopted to carry out this study.

Setting: The study was conducted in outpatient clinics of Aga Central Hospital at Dakahlia governorate. Participants:

All nurses who are working at outpatient clinics including baccalaureate nurses, technician nurses and diploma nurses.

\section{Sampling:}

Purposive sample all nurses in the previous outpatient clinics 70 nurse. 
Tools:

Data was collected by using four self-administered structured questionnaires

Tool1:self-administered tructured questionnaire to assess demographic and qualification data: to assess the occupational data of nurses such as (age, sex, qualification, and years of experience).

Tool2: elf-administered structured questionnaire to assess nurses' Knowledge regarding health education: this tool was used included the following items (general concept of health education, purposes, settings, principles, obstacles, elements, methods, materials, steps of health education and characteristics of health educator).

Tool 3: structured observation checklist: this checklist was used after conducted the simulation sessions to assess nurses' performance regarding the application of health education process.

Tool 4: self-administered structured questionnaire: this questionnaire used to assess:

- Nurses' perception regarding importance of health education: it was four Likert scale used to assess nurses' perception regarding importance of health education.

- Nurses' perception regarding simulation learning: it was four Likert scale used to assess nurses' perception regarding the simulation learning.

\section{Phases of the Study:}

This study was accomplished throughout two main phases

Phase 1: Preparation phase

Administrative process: An official letter was issued from the faculty of Nursing Mansoura University to the director of Aga Central Hospital that permits the researcher to carry out the study.

Literature review: Review of national and international literatures on the various aspects of health education using scientific published articles. This review was a guide for developing the study tools

Developing of the study tools:

* Tools of data collection were developed by the researcher based on reviewing the relevant literature.

* Validity of the study tools was tested by the following:

- Face validity by conducting a pilot study on $10 \%$ of the study sample $\mathrm{n}=7$ nurses.

- Content validity by submitting the tools to a jury of five experts in the field of community health nursing.

- The reliability (.061) of the evaluation scale of acceptance and satisfaction as measured by using the SPSS program.

Phase 2: Operational phase

Data collection:

- The data was collected during the period of August to October 2018 from nurses working in 12 clinics affiliated to Aga Central Hospital.

- The researcher introduced herself to nurses and gave them a brief orientation about aim of the study in order to gain their cooperation.

- Tools of data collection were distributed to the nurses at Aga central Hospital Hall before implementation of the training sessions tool 1,2 and collected immediately after being fulfilled.

- Tool 2, 3, 4 was used after implementation of the training.

Preliminary assessment: tool 2 was used to assess nurses' knowledge. The preliminary assessment revealed 
1Shaimaa Mostafa Abd Elaziz Almarhomy et. al.

poor knowledge related to health education.

Developing simulation training sessions: Based on the obtained data from the preliminary assessment, the researcher developed training sessions to improve nurses' knowledge and performance related to health education.

Implementation of simulation training sessions:

-The training sessions were implemented within working hours, for 7 nurses per session. Seven sessions were applied in three days every week and lasted for ten weeks (10 groups of nurses, each group included 7 nurses)

- Each session started with a brief summary of the previous session and objectives of the new session.

- The introductory session lasted for half an hour for nurses to fulfill both tool 1 and tool 2 for each group of nurses (7 nurses for each group), so that the introductory sessions for the hall simulation sessions lasted for three and half hours per ten weeks for all groups.

- Theoretical sessions conducted through the use of low fidelity simulation methods "brainstorming and group discussion using simple language and power point presentations" that suits to the level of nurses without ignoring motivation and reinforcement techniques.

- Practical sessions started by using low fidelity simulation methods "scenarios, case studies, demonstration and re-demonstration of health education process using real materials".

Evaluation of the simulation training sessions:

* Tool 2 was developed to assess the effect of using simulated learning on nurses' knowledge related to health education which lasted for 15 minutes for each group with total hours 1.75 hour per seven weeks for all groups.

* Tool 4 was distributed at the fifth session and lasted for 30 minutes for each group to be fulfilled with total hours 5 hours per 10 weeks for all groups and was used to evaluate:

- The nurses' perception toward importance of health education and using simulated learning on health education process was evaluated

- Tool 3 structured observation checklist: was used to evaluate nurse's performance during educational session for 30 minutes in the clinics. The researcher observed 7 nurses /day/week for 4 hours; so that observation of all nurses lasted for 40 hours/7days/10 weeks.

Data analysis: SPSS software package (Stand for Statistical Product and Service Solutions version 16.0) was used for data analysis. Descriptive statistics including frequency, distribution, mean and standard deviation were used to describe different characteristics.

Ethical consideration: An approval was obtained from Research Ethical Committee, faculty of nursing Mansoura University to accomplish this study.

Oral approval was obtained from the nurses. The researcher introduced herself and a simple explanation about the aim of the study would be given to them. They assured that their participation in the study was voluntary and that collected data will treat confidentiality and will be only used for the purpose of the study. Nurses would be informed that they had the right to withdraw at any time from the study. 


\section{Results}

Table (1) reflects that $(58.6 \%)$ of nurses age ranged between $30-40$ years and more with mean age of 34.6 (5.946) years old. Concerning their qualification, (64.3\%) of them has diploma degree of nursing. Regarding years of experience, $(58.6 \%)$ of nurses' experience ranged from 10-20 years with mean 1.87(.635). A few numbers of nurses $(27.1 \%)$ were working in dental unit while $(72.9 \%)$ of them were working in other clinics such as (orthopedic, pediatric, medical, dermatology, urology, surgery, ophthalmology and gynecology clinics).

Table (2) shows that $(82.9 \%)$ of nurses attended health education training sessions inside their workplace, while $(65.7 \%)$ of them attended health education training sessions outside their workplace. Nearly half of nurses $(45.7 \%)$ provided health education sessions in the hospital. Diabetes mellitus was the main health education topic provided by nurses in hospital.

Table (3) illustrates that $44.3 \%$ of nurses had fair score level of knowledge with a mean 1.16 (1.304) pre simulation learning intervention according their knowledge about purposes of health education. While, $98.6 \%$ of them had good knowledge score level post simulation learning intervention with a mean 4.69 (.468). There was statistically significant difference between pre and post-test regarding the previous item $(\mathrm{t}=$ $20.196, P \leq 0.01$ ) with a percent of change between pre and post simulation learning intervention $75.3 \%$.

In relation to knowledge regarding principles of health education $88.6 \%$ of the studied nurses had poor knowledge score level with a mean 1.23 (1.206) pre simulation learning intervention. While $100 \%$ of nurses had good knowledge score level post simulation learning intervention with a mean 4.93 (.259). There was statistically significant difference between pre and post-test regarding the previous item ( $\mathrm{t}=$ $25.131, \mathrm{P} \leq 0.01$ ) with a percent of change between pre and post simulation learning intervention $75 \%$.

It was observed that $52.9 \%$ of the studied nurses had fair knowledge score level with a mean of $1.37(1.169)$ pre simulation learning intervention regarding health education elements. However, $97.1 \%$ of them had good knowledge score level post simulation learning intervention with a mean 3.97 (.168). There was statistically significant difference between pre and post-test regarding the previous item

$(\mathrm{t}=17.998, \mathrm{P} \leq 0.01)$ with a percent of change between pre and post simulation learning intervention $65.5 \%$.

In relation to knowledge regarding settings of health education $70 \%$ of nurses had poor knowledge score level with a mean 2.26 (1.293) pre simulation learning intervention. While $98.6 \%$ of them post simulation learning intervention had good knowledge score level with a mean $4.90(.515)$. There was statistically significant difference between pre and post-test regarding the previous item $(\mathrm{t}=15.094, \mathrm{P} \leq 0.01)$ with a percent of change between pre and post simulation learning intervention $53.9 \%$.

Table (4) illustrates distribution of the studied nurses' pre and post simulation learning intervention. It was observed that $87.1 \%$ of the studied nurses had poor knowledge score level with a mean of 1.80(1.016) pre simulation learning intervention regarding methods of health education. However, $98.6 \%$ of them had good knowledge score level post simulation learning intervention with a mean 5.91(.329). There was statistically 
1Shaimaa Mostafa Abd Elaziz Almarhomy et. al.

significant difference between pre and post-test regarding the previous item $(\mathrm{t}=$ $31.754, \mathrm{P} \leq 0.01$ ) with a percent of change between pre and post simulation learning intervention $69.5 \%$.

In relation to knowledge regarding materials of health education $91.4 \%$ of studied nurses had poor score level of knowledge with a mean 2.56(2.217) pre simulation learning intervention. While their knowledge had good score level $97.1 \%$ post simulation learning intervention with a mean 11.81(.748). There was statistically significant difference between pre and post-test regarding the previous item $(\mathrm{t}=$ $30.693, P \leq 0.01)$ with a percent of change between pre and post simulation learning intervention $69.5 \%$.

It was observed that $50 \%$ of the studied nurses had poor knowledge score level with a mean of 2.34(1.261) pre simulation learning intervention regarding the characteristics of effective health educator. However, 98.6\% of them had good knowledge score level post simulation learning intervention with a mean 4.94(.289). There was statistically significant difference between pre and post-test regarding the previous item $(\mathrm{t}=17.013, \mathrm{P} \leq 0.01)$ with a percent of change between pre and post simulation learning intervention $62.6 \%$.

Regarding nurses' knowledge about obstacles of health education, it was observed that $82.9 \%$ of nurses had poor knowledge score level with a mean of 5.61(3.406) pre simulation learning intervention. However, $100 \%$ of them had good knowledge score level post simulation learning intervention with a mean 16.8(.734). There was statistically significant difference between pre and post-test regarding the previous item $(\mathrm{t}=$ $27.105, \mathrm{P} \leq 0.01$ ) with a percent of change between pre and post simulation learning intervention $66.6 \%$.

According to nurses' knowledge about the steps of health education, it was observed that $98.6 \%$ of nurses had poor score level of knowledge with a mean of .04(.359) pre simulation learning intervention. However, 97.1\% of them had good knowledge score level post simulation learning intervention with a mean 4.83 (.780). There was statistically significant difference between pre and post-test regarding the previous item $(\mathrm{t}=38.720, \mathrm{P} \leq 0.01)$ with a percent of change between pre and post simulation learning intervention $99.1 \%$.

Table (5) reveals nurses' performance level regarding application of health education process. It was observed that $(81.4 \%, 82.9 \%, 71.4 \%)$ of the studied nurses had the ability to identify the needs and interests of the recipients, assess the recipient's readiness to know the information and identify the points for which the recipients' needs respectively. However, $67.1 \%$ of them didn't have the ability to assess recipients' information on their needs.

Also, $55.6 \%$ of them had the ability to determine the general goal of health education provided to each recipient, $64.3 \%$ of them had the ability to set specific goals provided to each recipient. While $94.3 \%$ of them had the ability to determine the appropriate place and identify the right time for providing health education, and $64.3 \%$ of them had the ability to develop key points for scientific content and prepare the appropriate environment to provide health education.

According to the implementation of health education plan, $100 \%$ of them had been greeted the attendance, introduce herself to recipients, used appropriate language and method 
Effect of Using Simulated Learning on ...

appropriate to the level of recipient's perception, used clear voice and thanked the recipients for good listening. Additionally, $(94.3 \%, 88.6 \%)$ of them detected the subject of health education and encouraged the recipients to discuss and participate respectively.

About evaluation of health education plan, $77.1 \%$ of them evaluated and reviewed their information provided at the end of the program, however $62.9 \%$ of them didn't evaluate the recipients during the program presentation and $80 \%$ of them didn't conduct an assessment and didn't review the skills presented at the end of the program.

\section{Table (1):-Nurses' demographic and qualification characteristics}

\begin{tabular}{|c|c|c|}
\hline Items & $\mathrm{N}=70$ & $\%$ \\
\hline \multicolumn{3}{|l|}{ Age in years } \\
\hline $20-<30$ & 15 & 21.4 \\
\hline $30-<40$ & 41 & 58.6 \\
\hline$>40$ & 14 & 20 \\
\hline $\mathrm{X}^{-}(\mathrm{SD})$ & \multicolumn{2}{|c|}{$34.6(5.946)$} \\
\hline \multicolumn{3}{|l|}{ Qualification data } \\
\hline Baccalaureate of nursing & 16 & 22.9 \\
\hline Nursing technician & 9 & 12.9 \\
\hline Nursing Diploma & 45 & 64.3 \\
\hline \multicolumn{3}{|l|}{ Years of experience } \\
\hline $1-<10$ & 19 & 27.1 \\
\hline $10-20$ & 41 & 58.6 \\
\hline$>20$ & 10 & 14.3 \\
\hline $\mathrm{X}^{-}(\mathrm{SD})$ & \multicolumn{2}{|c|}{$1.87(.635)$} \\
\hline \multicolumn{3}{|l|}{ Working Clinics } \\
\hline Dental unit & 19 & 27.1 \\
\hline Other clinics & 51 & 72.9 \\
\hline
\end{tabular}

Table (2): Nurses' continuing education and training program

\begin{tabular}{|c|c|c|}
\hline Items & $\mathrm{N}=70$ & $\%$ \\
\hline \multicolumn{3}{|l|}{ Nurses attended health education training sessions } \\
\hline Inside their workplace & 58 & 82.9 \\
\hline Outside their workplace & 46 & 65.7 \\
\hline Nurses provided health education sessions inside their workplace & 32 & 45.7 \\
\hline \multicolumn{3}{|l|}{ Health education topics provided by nurses inside their workplace } \\
\hline Diabetes Mellitus & 9 & 12.9 \\
\hline Hand washing & 7 & 10 \\
\hline Hypertension & 5 & 7.1 \\
\hline Tooth decay prevention & 3 & 4.3 \\
\hline Bronchitis & 2 & 2.9 \\
\hline Diarrhea & 2 & 2.9 \\
\hline Family planning methods & 2 & 2.9 \\
\hline
\end{tabular}


1Shaimaa Mostafa Abd Elaziz Almarhomy et. al.

Table (3): Nurses' correct knowledge about health education purposes, principles, elements and settings pre $\&$ post simulation learning intervention $(n=70)$

\begin{tabular}{|c|c|c|c|c|}
\hline \multirow{2}{*}{ Knowledge Items } & \multicolumn{2}{|c|}{ Pre } & \multicolumn{2}{|c|}{ Post } \\
\hline & $\mathrm{N}$ & $\%$ & $\mathrm{~N}$ & $\%$ \\
\hline \multicolumn{5}{|c|}{ Total health education purposes $(\mathrm{score}=4)$} \\
\hline Poor & 30 & 42.9 & 0 & 0.0 \\
\hline Fair & 31 & 44.3 & 1 & 1.4 \\
\hline Good & 9 & 12.9 & 69 & 98.6 \\
\hline $\mathrm{X}^{-}(\mathrm{SD})$ & \multicolumn{2}{|c|}{$1.16(1.304)$} & \multicolumn{2}{|c|}{$4.69(.468)$} \\
\hline Paired t-test & \multicolumn{4}{|c|}{20.196} \\
\hline $\mathrm{P}$ & \multicolumn{4}{|c|}{$.000 * *$} \\
\hline$\%$ of change & \multicolumn{4}{|c|}{75.3} \\
\hline \multicolumn{5}{|c|}{ Total principles of health education $($ score $=5$ ) } \\
\hline Poor & 62 & 88.6 & 0 & 0.0 \\
\hline Fair & 4 & 5.7 & 0 & 0.0 \\
\hline Good & 4 & 5.7 & 70 & 100 \\
\hline $\mathrm{X}^{-}(\mathrm{SD})$ & \multicolumn{2}{|c|}{$1.23(1.206)$} & \multicolumn{2}{|c|}{$4.93(.259)$} \\
\hline Paired t-test & \multicolumn{4}{|c|}{25.131} \\
\hline $\mathrm{P}$ & \multicolumn{4}{|c|}{$.000 * *$} \\
\hline$\%$ of change & \multicolumn{4}{|c|}{75} \\
\hline \multicolumn{5}{|c|}{ Total elements of health education $($ score $=4)$} \\
\hline Poor & 31 & 44.3 & 0 & 0.0 \\
\hline Fair & 37 & 52.9 & 2 & 2.9 \\
\hline Good & 2 & 2.9 & 68 & 97.1 \\
\hline $\mathrm{X}^{-}(\mathrm{SD})$ & \multicolumn{2}{|c|}{$1.37(1.169)$} & \multicolumn{2}{|c|}{$3.97(.168)$} \\
\hline Paired t-test & \multicolumn{4}{|c|}{17.998} \\
\hline $\mathrm{P}$ & \multicolumn{4}{|c|}{$.000 * *$} \\
\hline$\%$ of change & \multicolumn{4}{|c|}{65.5} \\
\hline \multicolumn{5}{|c|}{ Total health education settings $($ score $=5$ ) } \\
\hline Poor & 49 & 70 & 1 & 1.4 \\
\hline Fair & 9 & 12.9 & 0 & 0.0 \\
\hline Good & 12 & 17.1 & 69 & 98.6 \\
\hline $\mathrm{X}^{-}$(SD) & \multicolumn{2}{|c|}{$2.26(1.293)$} & \multicolumn{2}{|c|}{ 4.90(.515) } \\
\hline Paired t-test & \multicolumn{4}{|c|}{15.094} \\
\hline $\mathrm{P}$ & \multicolumn{4}{|c|}{$.000 * *$} \\
\hline$\%$ of change & \multicolumn{4}{|c|}{53.9} \\
\hline
\end{tabular}


Effect of Using Simulated Learning on ...

Table (4): Nurses' correct knowledge about health education methods, materials, obstacles, steps and characteristics of effective health educator pre $\&$ post simulation learning intervention $(n=70)$

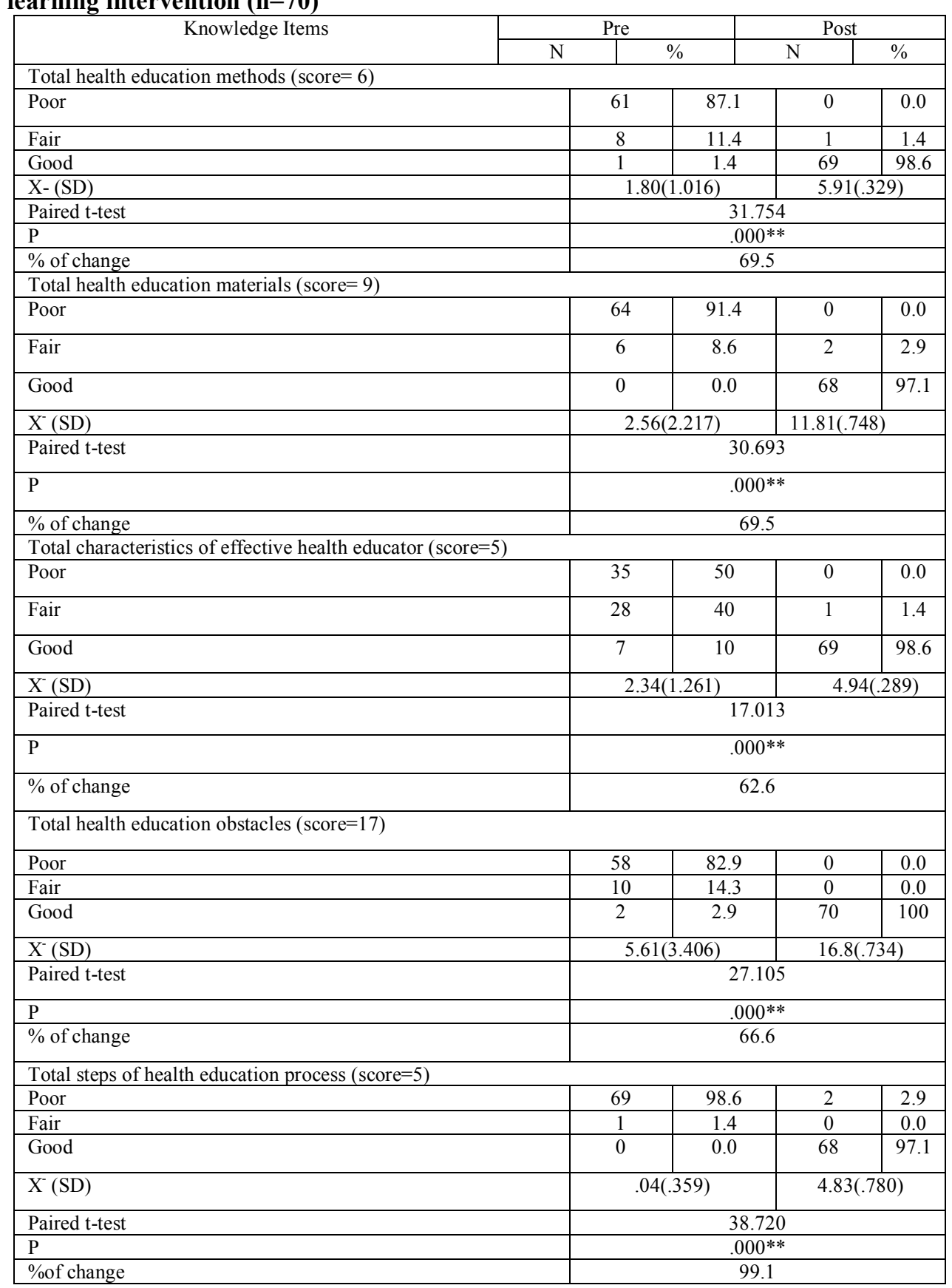


1Shaimaa Mostafa Abd Elaziz Almarhomy et. al.

\begin{tabular}{|c|c|c|c|c|}
\hline \multicolumn{5}{|c|}{$\begin{array}{l}\text { Table (5): Nurses' performance level regarding application of health education } \\
\text { process }(n=70)\end{array}$} \\
\hline \multirow[t]{2}{*}{ Item } & \multicolumn{2}{|c|}{ Satisfactory } & \multicolumn{2}{|c|}{ Unsatisfactory } \\
\hline & $\mathrm{N}$ & $\%$ & $\mathrm{~N}$ & $\%$ \\
\hline \multicolumn{5}{|l|}{ Recipient's assessment before planning } \\
\hline Identified the needs and interests of the recipients & 57 & 81.4 & 12 & 17.1 \\
\hline Identified the educational background of recipients & 40 & 57.1 & 30 & 42.9 \\
\hline Identified the points for which the recipients' needs health education & 50 & 71.4 & 20 & 28.6 \\
\hline Assessed recipients' information on these points & 23 & 32.9 & 47 & 67.1 \\
\hline $\begin{array}{l}\text { Assessed recipients' readiness and willingness to know the } \\
\text { information that is lacking }\end{array}$ & 58 & 82.9 & 12 & 17.1 \\
\hline \multicolumn{5}{|l|}{ Setting goals and objectives } \\
\hline $\begin{array}{l}\text { Ability to determine the general goal of health education provided to } \\
\text { each recipient. }\end{array}$ & 39 & 55.7 & 31 & 44.3 \\
\hline $\begin{array}{l}\text { Ability to set specific goals that will help in providing the best health } \\
\text { education for each recipient }\end{array}$ & 45 & 64.3 & 25 & 35.7 \\
\hline \multicolumn{5}{|l|}{ Developing a plan for health education program } \\
\hline Developed key points for the scientific content & 45 & 64.3 & 25 & 35.7 \\
\hline Prepared suitable teaching aids to display educational content & 38 & 54.3 & 32 & 45.7 \\
\hline Prepared examples and novels help explain the subject & 39 & 55.7 & 31 & 44.3 \\
\hline Determined the appropriate place for health education & 66 & 94.3 & 4 & 5.7 \\
\hline Identified the right time to provide health education & 66 & 94.3 & 4 & 5.7 \\
\hline Prepared the appropriate environment to provide health education & 45 & 64.3 & 25 & 35.7 \\
\hline \multicolumn{5}{|l|}{ Implementation of health education plan } \\
\hline Greeted the attendance & 70 & 100 & 0 & 0.0 \\
\hline Introduced herself to recipients & 70 & 100 & 0 & 0.0 \\
\hline Detected the subject of health education & 66 & 94.3 & 4 & 5.7 \\
\hline $\begin{array}{l}\text { Started by explaining simple information and increasing the depth of } \\
\text { information gradually }\end{array}$ & 30 & 42.9 & 40 & 57.1 \\
\hline $\begin{array}{l}\text { Used a detailed, complete and accurate explanation of each part of the } \\
\text { subject }\end{array}$ & 40 & 57.1 & 30 & 42.9 \\
\hline Used appropriate teaching methods & 41 & 58.6 & 28 & 40 \\
\hline $\begin{array}{l}\text { Used of language and method appropriate to the level of perception of } \\
\text { the recipients }\end{array}$ & 70 & 100 & 0 & 0.0 \\
\hline Used clear voice tone & 70 & 100 & 0 & 0.0 \\
\hline Encouraged the recipients to discuss and participate & 62 & 88.6 & 8 & 11.4 \\
\hline $\begin{array}{l}\begin{array}{l}\text { Conducted a summary and appropriate review of the subject } \\
\text { submitted }\end{array} \\
\end{array}$ & 55 & 78.6 & 15 & 21.4 \\
\hline Thanked the recipients for good listening & 70 & 100 & 0 & 0.0 \\
\hline \multicolumn{5}{|l|}{ Evaluation of health education plan } \\
\hline Evaluated the recipients during the presentation of the program & 26 & 37.1 & 44 & 62.9 \\
\hline $\begin{array}{l}\text { Evaluated and reviewed the information provided at the end of the } \\
\text { program }\end{array}$ & 54 & 77.1 & 16 & 22.9 \\
\hline $\begin{array}{l}\text { Conducted an assessment and reviewed the skills presented at the end } \\
\text { of the program }\end{array}$ & 14 & 20 & 56 & 80 \\
\hline
\end{tabular}


Effect of Using Simulated Learning on ...

Table (6): Nurses' perception regarding the importance of health education $(\mathbf{n}=70)$
\begin{tabular}{|l|l|l|l|l|l|}
\hline \multicolumn{1}{|c|}{ Item } & \multicolumn{2}{|l|}{ Agree } \\
\cline { 2 - 6 } & $\mathrm{N}$ & $\%$ & $\mathrm{~N}$ & $\%$ \\
\hline Health education is a process suitable for all age groups. & 2 & 2.8 & 68 & 97.2 \\
\hline $\begin{array}{l}\text { The health education process has a good impact on the lifestyle of } \\
\text { recipients. }\end{array}$ & 1 & 1.4 & 69 & 98.6 \\
\hline $\begin{array}{l}\text { Health education is a necessary requirement within health care } \\
\text { facilities. }\end{array}$ & 0 & 0 & 70 & 100 \\
\hline Training program for nurses on health education is important. & 1 & 1.4 & 69 & 98.6 \\
\hline Having a desire to provide health education services to citizens. & 5 & 7.1 & 65 & 92.8 \\
\hline Providing health education is essential for all nurses' work. & 1 & 1.4 & 69 & 98.6 \\
\hline $\begin{array}{l}\text { Providing health education is essential only for nurses who had } \\
\text { Bachelor of Nursing. }\end{array}$ & 6 & 95.7 & 3 & 4.3 \\
\hline $\begin{array}{l}\text { Health education should be provided by experts and specialists in } \\
\text { health education. }\end{array}$ & 3 & 4.3 & 67 & 77.7 \\
\hline$X^{-}($SD) & $22.7(2.39)$ & \\
\hline
\end{tabular}

Table (7): Nurses' perception regarding the use of simulation learning $(n=70)$

\begin{tabular}{|c|c|c|c|c|}
\hline \multirow[b]{2}{*}{ Item } & \multicolumn{2}{|c|}{ Disagree } & \multicolumn{2}{|c|}{ Agree } \\
\hline & $\mathrm{N}$ & $\%$ & $\mathrm{~N}$ & $\%$ \\
\hline Simulation learning is a flexible method. & 1 & 1.4 & 69 & 98.6 \\
\hline $\begin{array}{l}\text { The use of simulation education is a clear way to explain the content of the } \\
\text { health education program. }\end{array}$ & 2 & 2.8 & 68 & 97.2 \\
\hline Simulation methods are more interactive. & 3 & 4.3 & 67 & 95.8 \\
\hline Simulation methods are more exciting. & 2 & 2.9 & 68 & 97.1 \\
\hline Simulation teaching methods are more motivating. & 1 & 1.4 & 69 & 98.6 \\
\hline Simulation teaching methods are the most effective. & 2 & 2.8 & 68 & 97.1 \\
\hline Simulated learning methods provide more results and feedback on the content. & 4 & 5.7 & 66 & 94.3 \\
\hline Simulated learning methods can attract the attention of service recipients. & 1 & 1.4 & 69 & 98.5 \\
\hline $\begin{array}{l}\text { Methods of learning by simulation allow the recipient to apply and practice the } \\
\text { information learned better than just memorizing it. }\end{array}$ & 6 & 8.5 & 64 & 91.4 \\
\hline Simulation methods allow the recipient to explore information. & 10 & 14.3 & 60 & 85.7 \\
\hline $\mathrm{X}^{-}(\mathrm{SD})$ & \multicolumn{4}{|c|}{$22.8(2.62)$} \\
\hline
\end{tabular}

\section{Discussion:}

Health education is a profession of educating people about health. This profession encompasses environmental, physical, social, emotional, intellectual, and spiritual health, as well as sexual and reproductive health education (Kumar \& Preetha, 2012). Health education is one of the most important functions for promoting and maintaining of health (Duffy, 2018). Well-trained nurse about the importance and purpose of health education is helping in improving community health (Abdulla, 2019). Using simulation as an educational method is a very important tool in nursing education that promote effective learning by improving knowledge and clinical performance among nurses in clinical education (Shin, Park \& Kim, 2015).

Therefore, the current study is focused on using simulation as an educational method for outpatient nurses to improve their skills in applying health education process.

In relation to socio demographic characteristics of nurses, the present study revealed that more than one third of the studied nurses affiliated to the age group between 30-40 years with mean (SD) age of 34.6 (5.946). Moreover, all the studied nurses are females and the majority had diploma degree of nursing. Bland, Topping \& Wood (2012) found in 
1Shaimaa Mostafa Abd Elaziz Almarhomy et. al.

the study conducted in Oxford that one third of nurses had baccalaureate degree. Concerning to continuing education and training, the present study showed that more than two thirds of the studied nurses attended training sessions in the working place. This agrees with Chaghari, Saffari, Ebadei \& Ameryoun (2017) who reported that two thirds of nurses attended in-service training sessions that conducted in their working place in Tehran. In-service training is important fact that enhancing nurse's quality of care.

Concerning to knowledge of nurses about health education purpose, principles, method and materials, the present study revealed that two fifth of nurses who had poor knowledge related to purpose and principles and the majority related to method and materials of education before the simulated learning intervention. While after simulated learning intervention, their knowledge improved and there was statistically significant difference. These results are supported by other studies results that conducted in Saudi Arabia by Alsaleh (2016) who documented that structured simulated learning has a beneficial impact in improving the knowledge of nurses about purpose of health education. In Iran the following researchers Afshari, Ghahnaviyeh, Khezeli \& Daniali (2019) noted that simulated learning affect and improve nurses' knowledge about health education principles and in U.S.A the researchers; Friberg, Granum \& Bergh (2012) reported that most of nurses had knowledge about health education methods and materials after intervention.

As regard to knowledge of nurses about health education settings and characteristics of health educator, the present study approved that nurses who had poor knowledge about settings of health education nearly two thirds and around half of them related to characteristics of health educator but after the simulated learning intervention most of them their knowledge has been improved. These findings go well together with Springer et al (2017) findings, who reported that majority of studied nurses their knowledge about settings of health education improved after attended heath education program. Also, Bergh, Friberg, Persson\& Lyckhage (2015) found that majority of nurses in Sweden their knowledge about characteristics of health educator improved after intervention sessions.

As regards to nurses' knowledge about obstacles of health education, the findings of the present study revealed that the majority of studied nurses had poor knowledge about obstacles facing conduction of health education before applying the simulated learning intervention but most of nurses their knowledge improved after simulated learning intervention.

These findings go well together with Anbari \&Ramezani (2010) findings in medical sciences Arak University, Ghorbani (2014) in Iran and by Azimi (2017) in Tabriz; these studies revealed that teaching obstacles of education by simulation improved nurses' knowledge related this subject in addition, the studied nurses found ways to overcome educational obstacles by creating available solutions. Such educational programs should be adopted in clinical settings to enhance knowledge, performance and attitude of community health nurses (Mavin et al, 2019). The present study demonstrates significant improvement of the total knowledge about health education after applying the simulated learning intervention. This 
Effect of Using Simulated Learning on ...

finding is in the harmony with Cook et al (2011) findings in U.K. who approved that simulation training had been enhanced knowledge outcomes of health care professional learners.

This in contrast with Zaheya, Gharaibeh \& Alostaz (2012) findings who reported that neither knowledge acquisition nor knowledge retention showed any significant differences after high fidelity simulation of nurses' students in Jordan.

Regarding nurse's performance of health education process, the current study revealed that about two thirds of studied nurses assessed their recipient's needs, interests, educational background, information about the introduced topic and readiness to receive information before planning of health education program. This finding is in harmony with Krall et al (2016) founding, who illustrated that majority of staff nurse educators had been able to assess patients with diabetes mellitus before applying health education program to decline time of patients' hospitalization and foster patients transition to outpatient follow up.

Nurses' performance regarding setting goals and objectives, the present study found that two thirds of the studied nurses wrote specific objectives according to Bloom's Taxonomy and related to health education subject while about more than half of them have wrote general goals for each subject. This result is in harmony with Adams (2015) results who revealed that health care educators had to use Blooms Taxonomy to train and instruct health care providers to write learning objectives that describe the skills and abilities of their learners to master and demonstrate.

Nurses performance regarding developed a plan for health education program, the current study found that about nearly two fifth of studied nurses developed a plan for health education and nearly half of them were not preparing suitable teaching aids. This finding comes in line with Hudson \& Macdonald (2010) finding who demonstrated that majority of nurses successfully developed a health education plan to prepare patients for home hemodialysis in Canada.

Regarding implementation and evaluation of health education plan the present study revealed that the majority of the studied nurses who implemented simulated learning had high scores in greeting and introducing themselves to the recipients, using of appropriate language, teaching method and used clear voice tone This result is congruent with Hargreaves (2013) result who revealed that the majority of educators had the ability to apply effective health education programs in New Zealand. In addition, majority of nurses who are working in teaching hospitals of Sari in Iran showed high scores in implementing health education programs as reported by Edrisi et al (2013). While three fourths of the studied nurses were able to evaluate the approved health education program with high scores related to presentation skills, information provided, evaluating recipients during the session and the ended session. These findings are in harmony with Lagger, Pataky \& Golay (2010) founding's who reported that majority of nurses in Ireland revealed that when evaluating patient outcomes related to continuous education about chronic diseases and obesity; which means improvement of health education provided to those patients.

According to nurses' perception regarding the importance of health education, the present study found that 
majority of studied nurses agreed that health education is a process suitable for all age groups. This study is not in the same line with Al Enazi (2017) who found that majority of students engaged in a clinical simulation experience in their healthcare program have a high agreement with the statement that simulation experience was not suitable for all age group in Georgia.

In relation to nurses' perception regarding the importance of health education, most of the studied nurses agreed that health education has a good effect on the recipient's lifestyle. This study is in the harmony with the study Amraei et al., (2020) study who reported that a health education program helps nurses to improve recipients' preventive behaviors (modifying their dietary regime and lifestyle) to acquire cardiovascular diseases. Also, this study is in the same line with Hoseini, Maleki \& Sharifirad (2014) study who showed that training program based on health education models had great effect in recipient's lifestyle for controlling blood pressure in Isfahan.

In relation to nurses' perception regarding the importance of health education, the present study found that most of nurses agreed that health education is necessary requirement in the health facilities. This study is in harmony with Duits, Kuks \&Busari (2020) study who demonstrated that health education programs have an important role in decreasing the need for more medical and financial resources because health education help in preventing complications that impact in decreasing the length of patient's stay in hospitals in Caribbean.

In relation to nurses' perception regarding the importance of health education, the present study revealed that the hospital's training program on health education is important and should be provided by experts and specialists as mentioned by most of nurses. This study is in the same line with Garrigues et al., (2019) study who revealed that training of Australian health professionals on health education was effective in increasing their knowledge, skills and attitudes. In addition, training most of healthcare providers on applying health education are important for creating more specialists in health education as conducted in U.S.A. by alber, paige \& stellefson (2016). While it is in contrast with the study conducted in Western Sweden by bergh et al., (2012) who found that most of the managers underestimated the importance of patient education so that they didn't save time for training nurses about health education.

Education is a clear way to explain the content of health education program in addition Moreover, majority of studied nurses agreed that using of simulated; most of them agreed that teaching methods by simulation are more effective and more motivated. These findings are consistent with the following studies; in China by Zhu \& Wu (2016) who showed that nurses were satisfied with simulation as a teaching method because it provides clear objectives and messages. In India, a study conducted by Krishnan, Keloth \& Ubedulla (2017) who demonstrated that simulation-based education is a rapidly developing discipline which can provide effective and safe learning environment for medical students. In Australia, a study conducted by Buykx et al., (2011) who showed that using simulation in nursing education is more motivated and effective in improving their performance and psychomotor skills. 
As regards to the relationships between demographic and qualification data and total knowledge score in the pre and post simulated learning intervention, it reveals a significant positive relation between increased knowledge score of post simulated learning intervention in relation to age, years of experience and qualifications of the studied nurses. This study is in the same line with Mohamed (2017) study who reported that thirty fourths of nurses in Egypt had a significant positive relation between knowledge about infection control after the training sessions and their age and qualifications.

Regarding to relationships between demographic, qualification data and total performance score in the pre and post simulated learning intervention, a significant positive relation between increased performance score of post simulated learning intervention in relation to age, years of experience and qualifications of the studied nurses. This finding was congruent with Friberg, Granum \&Bergh (2012) who revealed that there was a positive significance relation between nurses' performance in applying patient education after applying educational strategies and nurses' age, years of experience and qualification.

Concerning relationship between the nurses' demographic, years of experience and qualification and the nurses' perception regarding importance of health education, the current study reported that there was a statistically significant difference between total perception regarding the importance of health education and age, years of experience and qualification. This finding is in the harmony with Kemppainen, Tossavinen \& turunen (2013) findings who reported that there was a positive significant relation of nurses' perception in relation to age, years of experience and qualification in Eastern Finland.

In relation to relationship between the nurses' demographic, years of experience, qualification and the nurses' perception regarding to the use of simulation learning, this study found that there was a positive significant relation between nurses' age, years of experience, qualification and the nurses' perception regarding to the use of simulation learning. This current study is in relation to the study of Tosterud, Hedelin \& HallLord (2013) who indicated that nursing students were significantly satisfied with simulation learning methods.

\section{Conclusion:}

The main conclusion drawn from the present study revealed that nurses' knowledge and performance related to health education were poor in the preprogram while their knowledge and performance improved in the post program.

There is significant positive relation between increased knowledge, performance and use of simulation learning score of post simulated learning intervention in relation to age, years of experience and qualifications of the studied nurses.

Recommendations:

Staff development educators can create carefully crafted simulations that will assist in developing the expertise needed to meet the current challenges in nursing and healthcare at large.

Continuous supervision and evaluation of nurses in hospital to determine any defect related to performance of applying health education process. 


\section{References}

Abdulla, K., M., A. (2019): An assessment framework for walkability in Libyan city centres: public spaces in Tripoli: A Literature review, Nottingham Trent University.

Adams, N., E. (2015): Bloom's taxonomy of cognitive learning objectives: A Literature review, Journal of the Medical Library Association, Volume (103), Issue (3), Pp. 152-153.

Afshari, A., Ghahnaviyeh, L., A., Khezeli, M., \& Daniali, S., S. (2019): Health promotion perception among health-care providers working in educational hospitals of Isfahan, Iran: A Qualitative study: A Literature review, Journal of education and health promotion, Volume (8), Pp. 144.

Alber, J., M., Paige, S. \& Stellefson, M. (2016): Social Media SelfEfficacy of Health Education Specialists: Training and Organizational Development Implications: A Literature review, SAGE Journals, Volume (17), Issue (6).

Al Enazi, F., H. (2017): healthcare students' perceptions of simulation education at an urban: university: A Literature review, Georgia State University, Volume (18), Issue (1).

Alsaleh, N., S., M. (2016): Identifying health education competencies for primary health care nurses in Saudi Arabia: a Delphi Consensus Study: A Literature review, EThos.
Amaraei, S., G., Malekshahi, F., Goudarzi, F. \& Ebrahimzadeh, F. (2020): Using an educational program based on health belief model to improve the preventive behaviors of nurses against cardiovascular diseases: A Literature review, Journal of Education and Health Promotion, Volume (9), Pp. 100.

American Nurses Association (ANA) (2015): Scope and standards of Practice, $3^{\text {rd }}$ ed., Silver Spring, Georgia, Pp. 200- 202.

Anbari, Z. \& Ramezani, M. (2010): The obstacles of clinical education and strategies for the improvement of quality of education at Arak university of medical sciences in 2008: A Literature review, Journal of Arak University of Medical sciences, Volume (13), issue (2), Pp. 110-118.

Ander, D., S., \& Love, J., N. (2017): The Evolving Definition of Education Scholarship: What the Clinician Educator Needs to Know: A Literature review, West J Emerg Med., Volume (18), Issue (1), Pp. 1-3.

Azimi, M. (2017): The experience of education and training and health education specialists with available obstacles on aspects of planning health education and health promotion in schools with emphasis on problem solving solutions, Scientific Journal of Education Strategy in Medical Sciences, Volume (10), Issue (4), Pp. 245-254. 
Beilner, J., \& Leonard, M. A. (2017): The importance of continuous education in health care: A Literature review, Health Management, Volume (17), Issue (2).

Bergh, A., L., Friberg, F., Persson, E., \& Lyckhage, E., D. (2015): Registered Nurses' Patient Education in Everyday Primary Care Practice: Managers' Discourses: A Literature review, SAGE, Pp. 1-12.

Bergh, A., L., Karlsson, J., Persson, E. \& Friberg, F. (2012): Registered nurses' perceptions of conditions for patient educationfocusing on organisational, environmental and professional cooperation aspects: A Literature review, Journal of Nursing Management, Volume (20), Pp. 758-770.

Bland, A., J., Topping, A. \& Wood, B. (2012): A concept analysis of simulation as a learning strategy in the education of undergraduate nursing students: A Literature review, Nurse Education Today, Elsevier, Volume (31), Issue (7), Pp. 664- 670.

Buykx, P., Kinsman, L., Cooper, S., McConne-Henry, T., Cant, R., Endacott, R. \& Scholes, J. (2011): FIRST2ACT: Educating nurses to identify patient deterioration-A theory-based model for best practice simulation education: A Literature review, Nurse Education Today, Volume (31), Pp. 687-693.
Chaghari, M., Saffari, M., Ebadei, A. \& Ameryoun, A. (2017): Empowering Education: A New Model for In-service Training of Nursing Staff: A Literature review, J Adv Med Educ Prof, Volume (5), Issue (1), Pp. 26- 32.

Clement, I. (2012): Manual of community health nursing. 1st ed., Ltd.,Noida. Pp. 318-320.

Cook, D., A., Hatala, R., Brydges, R., Zendejas, B., Wang, A., T., Erwin, P., J., \& Hamstra, S., J. (2011): Technology-enhanced simulation for health professions education: a systematic review and meta-analysis: A Literature review, Quality assessed reviews, UK, https://www.ncbi.nlm.nih.gov/boo ks/NBK81848/

Duffy, J., R. (2018): Quality caring in nursing and health systems, 3rd ed., Springer, U.S.A., Pp. 264-265.

Duits, A., J., Kuks, J., B. \&Busari, J., O. (2020): Global health education in the Dutch Caribbean: 50 years of a unique GroningenCuraçao clinical clerkship program: A Literature review, Journal of Global Health Reports, Volume (4).

Edrisi, M., Khademloo, M., Ghorban, A., A., Gooran, F., Azandehi, H., K., Bahrami, B. \& Hesamzadeh, A. (2013): Self Report of Health Promoting Behaviors of Nurses Working in Teaching Hospitals: Literature review, Journal of Mazandaran University of Medical sceinces, Volume (23), Issue (105), Pp. 5259. 
Ervin, N. E., \& Kulbok, P. A. (2018): Advanced public and community health nursing practice: Population assessment, program planning and evaluation, $2^{\text {nd }}$ ed., Springer, U.S.A. Pp. 20-45.

Friberg, F., Granum, V., \& Bergh, A., L. (2012): Nurses -patienteducation work: conditional factors an integrative review, Journal of Nursing Management, Volume (20), Pp. 170-186.

Garrett, B., M., Macphee, M. \& Jackson, C. (2011): Implementing high-fidelity simulation in Canada: Reflections on 3 years of practice: A Literature review, Nurse Education Today, Elsevier, Volume (31), Issue (7), Pp. 671676.

Garrigues, M., P., Whitehead, D.,Pardavila-Belio, M., I., Canga-Armaryor, A., PueyoGarrigues, S. \& CangaArmaryor, N. (2019): Health education: A Rogerian concept analysis: A Literature review, International Journal of Nursing Studies, Volume (94), Pp. 131138.

Ghorbani, R., Soleimani, M., Zeinali, M., R., Davaji, M. (2014): Iranian nurses and nursing students' attitudes on barriers and facilitators to patient education: A survey study, Nurse Education in Practice, Elsevier, Volume (14), Pp. 551-556.

Hargreaves, A. (2013): The perceived value of Health Education in schools: New Zealand secondary teachers' perceptions: A Literature review, Journal of Curriculum Studies, Volume (45), Issue (4), Pp. 560-582.
Holzemer, S. P., \& Klainberg, M. (2014): Community health nursing: An alliance for health, $2^{\text {nd }}$ ed., Jones\& Bartlett Learning, U.S.A. Pp. 258-265.

Hoseini, H., Maleki, F., \& Sharifirad, G., R. (2014): Investigating the effect of an education plan based on the health belief model on the physical activity of women who are at risk for hypertension: A Literature review, Iranian Journal of Nursing and Midwifery Research, Volume (19), Issue (6), Pp. 647-652.

Hudson, S. \& Macdonald, M. (2010): Hemodialysis Arteriovenous Fistula Self-cannulation:

Moving Theory to Practice in Developing Patient-Teaching Resources: A Literature review, Clinical Nurse Specialist, Volume (24), Issue (6), Pp. 304-312.

Jung-Hee, K., Jin-Hwa, P., \& Sujin, S. (2020): Effectiveness of simulation-based nursing education depending on fidelity: A Literature review, BMC Medical Education, Volume (16), Issue (1).

Kemppainen, Tossavinen \& turunen (2013): Nurses' roles in health promotion practice: an integrative review: A Literature review, Health Promotion Intervational, Volume (28), Issue (4), Pp. 490501.

Krall, J., S., Donihi, A., C., Hatam, M., Koshinsky, J. \& Siminerio, L. (2016): The Nurse Education and Transition (NEAT) model: educating the hospitalized patient with diabetes: A Literature review, Clinical Diabetes and Endocrinology, Volume (2), Issue (1), Pp. 1-6. 
Effect of Using Simulated Learning on ...

Krishnan, D., G., Keloth, A., V. \& Ubedulla, S. (2017): Pros and cons of simulation in medical education: A Literature review, Volume (3), Issue (6), Pp. 84-87.

Kumar, S. \& Preetha, G., S. (2012): Health Promotion: An Effective Tool for Global Health: A Literature review, Indian Journal of Community Medicine, Volume (37), Issue (1), Pp. 5-12.

Lagger, G., Pataky, Z. \& Golay, A. (2010): Efficacy of therapeutic patient education in chronic diseases and obesity: A Literature review, Patient Education and Counseling, Volume (79), Issue (3), Pp. 283-286.

Mavin, T., J., Janssens, S., Kikkawa, Y., Hodge, S., \&Dickie, R. (2019): Cross-sector investigation into simulator-based training for maternity emergency management: competence-based issues: A Literature review, International Journal of Training Research, Volume (17), issue (2), Pp. 116139.

Mohamed, M., N., E. (2017): Training the Trainer Nurses on Infection Control at Student Hospital: A Literature review, Tanta Scientific Nursing Journal, Volume (13), Pp. 76-89.

Nestel, D., Kelly, M., Jolly, B. \&Watson, M. (2017): Healthcare simulation education: Evidence, Theory and Practice, $1^{\text {st }}$ ed., Wiley Blackwell, India, Pp. 5-9.

O'Connell, A., M. \& Fry-Bowers, E., K. (2011): Knowledge and Perceptions of Health Literacy Among Nursing Professionals: A Literature review, Journal of Health Communication, Volume (16), Issue (3).

Potter, P.A., \& Perry, A.G., \& Stockert, P.A., \& Hall, A.M. (2018): Essentials for nursing practice, $9^{\text {th }}$ ed., Elsevier, Canada, Pp. 201-220.
Shin, S., Park, J., H. \& Kim, J., H. (2015): Effectiveness of patient simulation in nursing education: Meta-analysis: A Literature review, Nurse Education today, Volume (35), Issue (1), Pp. 176182.

Springer, A., E., Evans, A., E., Ortuño, J., Salvo, D., \& Arévalo, M., T.,V. (2017): Health by Design: Interweaving Health Promotion into Environments and Settings: A Literature review, Front public health, Volume (5), Pp.268.

Tanaka, H., \& Tamura, N., (2016): Sleep education with self-help treatment and sleep health promotion for mental and physical wellness in Japan: A Literature review, Volume 14, Pp. 89-99.

Tosteru Tosterud, R., Hedelin, B. \& Hall-Lord, M., L. (2013): Nursing students' perceptions of high- and low-fidelity simulation used as learning methods: A Literature review, Nurse Education in Practice, Volume (13), Issue (4), Pp. 262-270.

Zaheya, L., M., A., Gharaibeh, M., K., \& Alostaz, Z., M. (2012): Effectiveness of Simulation on Knowledge Acquisition, Knowledge Retention, and SelfEfficacy of Nursing Students in Jordan: A Literature review, Clinical Simulation in Nursing, Volume (9), issue (9), Pp. 335342.

Zhu, F., F. \& Wu, L., R. (2016): The effectiveness of a high-fidelity teaching simulation based on an NLN/Jeffries simulation in the nursing education theoretical framework and its influencing factors: A Literature review, Chinese Nursing Research, Volume (3), Pp. 129-13 